\title{
Experimental Analysis of the Basic Mechanical Properties of Recycled Concrete
}

\author{
Shimin Zhang*, Sheliang Wang, Wei Liu and Mingming Zhang \\ Civil engineering college, Xijing University, Xian710123, China \\ *Corresponding author
}

\begin{abstract}
The cube compressive strength, splitting tensile strength and flexural strength of $\mathrm{C} 30$-level recycled concrete were tested, which was based on the testes of natural concrete. The kinds of recycled aggregates' service lives were $\mathbf{0}$ year, 10 years and 40 years, and the substitution rates were $30 \%, 50 \%$, $70 \%$ and $100 \%$. The experimental results indicate that the fracture morphology and process of the cube compressive strength, splitting tensile strength and flexural strength of the recycled concrete are consistent with the ones of the natural concrete. In the case of the same water-cement ratio, the cube compressive strength of recycled concrete is higher than the ordinary one, and the splitting tensile strength is lower than the ordinary one. The flexural strength of the recycled concrete is higher than the ordinary one, the one of the substitution rate of $50 \%$ is lower than ordinary one; In addition, it indicates that the concrete strength will be influenced by the life of recycled coarse aggregate.
\end{abstract}

Keywords-recycled coarse aggregate; recycled concrete; life; compressive strength; splitting tensile strength; flexural strength

\section{INTRODUCTION}

With the sustained and rapid development of economy in China, a large number of old concrete structures were demolished every year. On the other hand, there is also producing a large amount of new concrete buildings. In the process of demolition, wasted concrete is mainly destined for the outer suburbs stacking or landfilling. A large number of concrete raw materials needed in the construction process is produced by quarrying, digging and panning. Both that cause serious damage and waste of resources of ecological Environment.

If a large amount of waste concrete can recycle, not only it can solve the problem of the difficulty to deal with a lot of waste concrete and the deterioration of the ecological environment day by day, but also with recycled waste concrete aggregate substitutes natural aggregates for the construction industry can reduce the consumption of natural aggregates. Thereby that can reduce the exploitation of natural freestone, relieve pressure of natural aggregates increasingly scarce and reduce the damage of ecological environment due to the large number of freestone was mined.

Therefore, we should understand the basic mechanical properties of regeneration concrete and promote the use of recycled concrete. The related tests analysis and study basic mechanical properties of regeneration concrete.

\section{RAW MATERIALS, MIX PROPORTION AND TEST METHODS}

\section{A. Raw Materials of Test}

Strength grade of Cement is 32.5. Sand is ordinary sand. Modulus of fineness is 2.75. Natural coarse aggregate is gravel of continuous grading. Its maximum grain size is $31.5 \mathrm{~mm}$. Recycled coarse aggregate was abandoned concrete from demolished buildings and it was crushed by the artificial and jaw crusher. Then it was formed by cleaning and grading .The maximum of grain size is $31.5 \mathrm{~mm}$, and having well-graded. Water is tap water.

According to the needs of experiment and samples species of drawing materials, the experiment divides the recycled coarse aggregate into three categories. Recycled coarse aggregate of the first kind is broken concrete of the age of 0 years, and referred to as "0 years of recycled coarse aggregate, as R0. And the main source is wasting concrete component from laboratory. Recycled coarse aggregate of the second kind is broken concrete of the age of 10 years, and referred to as "10 years of recycled coarse aggregate, as R10. And the main source is wasting concrete component from Xian. Recycled coarse aggregate of the third kind is broken concrete of the age of 40 years, and referred to as "40 years of recycled coarse aggregate, as R40. And the main source is wasting concrete component from Xian.

\section{B. Mix Proportion of Recycled Concrete}

Concrete specimens divided into 13 groups. Number is $\mathrm{N}$ 、 R0-30, R0-50, R0-70, R0-100, R10-30, R10-50, R10-70, R10100, R40-30, R40-50, R40-70 and R40-100(N represents ordinary concrete, R0-30 $\sim \mathrm{R} 40-100$ represent 0 years recycled coarse aggregate, 10 years recycled coarse aggregate, 40 years recycled coarse aggregate, and recycled concrete's replacement rate is $30 \%, 50 \%, 70 \%$ and $100 \%)$.

The test of mixing proportion relies to the designing method of mix proportion of ordinary concrete in "Specification for Mix Proportion Design of Ordinary Concrete (JGJ 55-2000)". Using recycled aggregate water absorption in advance method designs for recycled concrete's mix proportion [1]. And water cement ratio was 0.37 . Sand ratio was $28 \%$.

\section{Test Method}

According to "Ordinary concrete mechanical performance test method standards", the experiment tested the compressive 
strength, splitting tensile strength and flexural strength. Loading speed of compressive strength test was per second $0.5 \mathrm{MPa}$. Loading speed of splitting tensile strength and flexural strength tests were per second 0.05MPa. Compressive strength and splitting tensile strength used the test sample being a cube of $100 \mathrm{~mm} \times 100 \mathrm{~mm} \times 100 \mathrm{~mm}$. And flexural strength used the test sample being a cube of $100 \mathrm{~mm} \times$ $100 \mathrm{~mm} \times 100 \mathrm{~mm}$.

\section{TEST RESULTS}

\section{A. Failure Mode}

Failure mode of the recycled concrete is as follows: In compression testing process of concrete cube, at first cracks near in the side surface of the test piece and it is coterminous inverted "八" shape. As the load continues to increase, the outer surface of the concrete began to drum and peel. The final failure modes is positive inverted attached the four corners cone (See Figure. I).

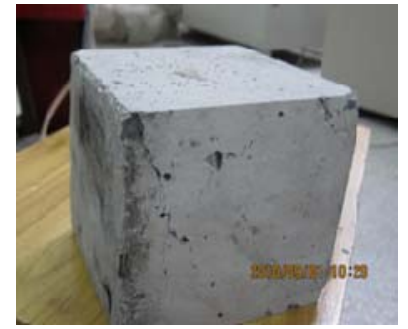

FIGURE I. URE COMPRESSION DAMAGE FORM.

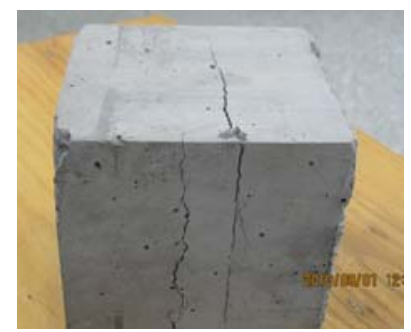

FIGURE II. FRACTURING FORM.

Failure mode of the recycled concrete is as follows: In the process of concrete splitting tensile test, and at the preliminary stage of loading, no cracks appeared on the surface of recycled concrete specimens. With the increase of load, the stress in the specimen is increasing. Cracks appears on the side surface of the specimen and firstly in the center of the specimen. Along with the load continue to increase, the cracks are gradually developing to the near of pad. When the load continues to increase, the crack width in the middle of recycled concrete is gradually increasing. At last the recycled concrete is split (See Figure.II).

Failure pattern of the recycled concrete is as follows: at the preliminary stage of loading, no cracks appear on the surface of recycled concrete specimens. With the increase of load, the bottom surface of the specimen is beginning to appear slight cracks. Cracks occur between the two concentrated loads load on the specimen. Along with the load continue to increase; Crack gradually extends vertically along the side surface. When the load continues to increase, the crack width of recycled concrete specimen increases gradually, and the final recycled concrete is broken (See Figure.III).
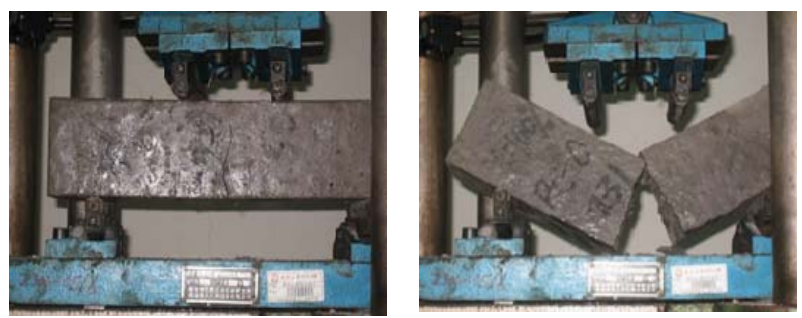

FIGURE III. FLEXURAL FAILURE FORM OF RECYCLED CONCRETE.

From the view of failure process and damage form, compressive strength, splitting tensile strength and flexural strength of the recycled concrete cube are the same as common concrete.

\section{B. Strength Test Results}

TABLE I. PERFORMANCE INDEX OF NATURAL AGGREGATE AND RECYCLED AGGREGATE.

\begin{tabular}{cccc}
\hline No. & $f_{c}(\mathrm{MPa})$ & $f_{t}(\mathrm{MPa})$ & $f_{f}(\mathrm{MPa})$ \\
\hline $\mathrm{N}$ & 32.70 & 3.42 & 3.83 \\
$\mathrm{R} 0-30$ & 35.98 & 2.96 & 3.81 \\
$\mathrm{R} 0-50$ & 34.68 & 3.02 & 3.59 \\
$\mathrm{R} 0-70$ & 39.52 & 3.34 & 4.17 \\
$\mathrm{R} 0-100$ & 39.35 & 3.26 & 4.34 \\
$\mathrm{R} 10-30$ & 37.98 & 3.13 & 4.13 \\
$\mathrm{R} 10-50$ & 31.54 & 2.91 & 3.64 \\
$\mathrm{R} 10-70$ & 31.05 & 2.95 & 3.72 \\
$\mathrm{R} 10-100$ & 32.31 & 2.57 & 4.05 \\
$\mathrm{R} 40-30$ & 34.51 & 3.16 & 3.98 \\
$\mathrm{R} 40-50$ & 36.64 & 3.15 & 3.88 \\
$\mathrm{R} 40-70$ & 39.16 & 3.42 & 4.28 \\
$\mathrm{R} 40-100$ & 39.73 & 3.26 & 3.88 \\
\hline
\end{tabular}

\section{TEST ANALYSIS}

\section{A. Basic Mechanical Properties of Recycled Concrete}

\section{1) Cube compressive strength}

Research on compressive strength of recycled concrete, some domestic and foreign scholars such as Malhotra, Frondistou-Yannas [2], and Jianzhuang Xiao [3] believe that the compressive strength of recycled concrete is lower than that of ordinary concrete. And the reduction range was between 5\% 24\%. In this experiment, from table 1 and Figure 4, we can see that the compressive strength of C30-level recycled concrete is higher than that of normal concrete in 28 days. And with the increase of substitution rate, it is increasing .And the increase of it is within $21 \%$, which is opposite to the results of the above research. 


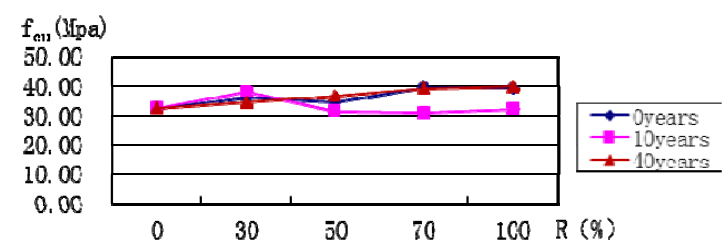

FIGURE IV. COMPRESSIVE STRENGTH CURVE OF RECYCLED COARSE AGGREGATE CONCRETE UNDER DIFFERENT LIVES AND DIFFERENT SUBSTITUTION RATES.

After research and analysis, the reasons for the improvement of the compressive strength of recycled concrete are as follows: (1) after two levels of crushing manually and mechanically, the cement paste with the poor adhesive natural aggregate and the cement and natural aggregate with cracks between the cement and natural aggregate can be removed. And the strength of remaining coarse aggregate is relatively high; (2) Recycled coarse aggregate surface is rough, so the friction coefficient between the coarse aggregate and the cement paste is increased. And the friction force of the interface is increased during the compression process. Regeneration coarse aggregate on water absorbing rate is larger, and equivalent to a "tank". In the process of concrete mixing water, recycled aggregates absorb and store water. Then in the process of concrete curing, with the progress of the cement hydration, it gradually released and formed a "Internal curing ".

\section{2) Splitting tensile strength}

The tensile strength of recycled concrete at home and abroad is relatively small. In the splitting tensile test, Li Jin [4] safely draws the conclusion that the recycled concrete splitting tensile strength reduced by $30 \% \sim 40 \%$ than ordinary concrete. In the recycled concrete under uniaxial tensile test, Jian Zhuang Xiao, Yang Lan [5] draw the conclusion that the tensile strength of recycled concrete reduced by $31 \%$ than ordinary concrete. In this experiment, it can be seen that the split tensile strength of C30 recycled concrete is lower than that of ordinary concrete at 28 days from table 1 and figure 5 . And the decrease amplitude is less than 25\%. The tensile strength of recycled concrete is basically formed a wavy curve by the change of the substitution rate. The curve in the replacement rate of $0 \% \sim 50 \%$ presents a downward trend, and the replacement rate of $50 \%$ is the lowest. And then with the increase of the substitution rate, the peak point is reached when the replacement rate is $70 \%$. Finally, with the increase of the replacement rate, it is decreasing.

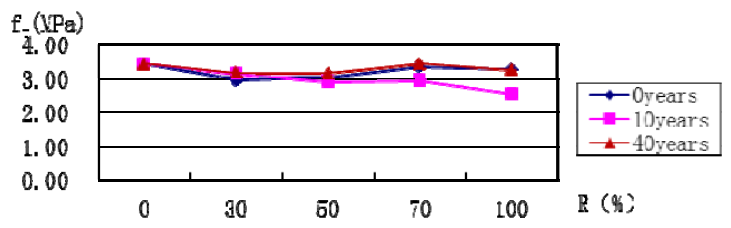

FIGURE V. SPLITTING STRENGTH CURVE OF RECYCLED COARSE AGGREGATE CONCRETE UNDER DIFFERENT LIVES AND DIFFERENT SUBSTITUTION RATES.
Through the research and analysis, the reasons for the decrease of the splitting tensile strength of recycled concrete are as follows: (1) the internal defects of recycled concrete and a large number of micro cracks have a great influence on the tensile damage, which is very small on compression failure. (2) The bond strength between the recycled coarse aggregate and the cement paste is relatively small. When it is pulled, it is extremely easy to crack. Although the friction coefficient of recycled aggregate and cement stone interface is relatively large, the impact of resistance to tensile strength is small.

\section{3) Flexural strength}

For the flexural strength of recycled concrete, Kawamura [6] and the Ahmad [7] do experiments and show that the flexural strength of recycled concrete is almost the same as that of ordinary concrete. In this experiment, it can be seen that the flexural strength of recycled concrete is close to that of ordinary concrete from table 1 and Figure VI. However the replacement rate of $50 \%$ is low.

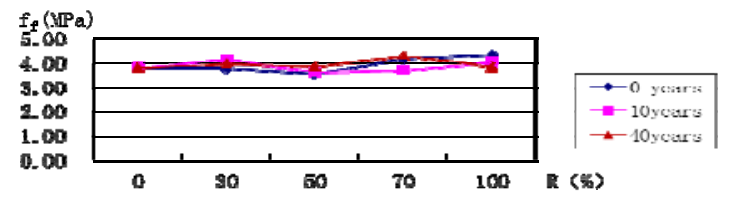

FIGURE VI. FLEXURAL STRENGTH CURVE OF RECYCLED COARSE AGGREGATE CONCRETE UNDER DIFFERENT LIVES AND DIFFERENT SUBSTITUTION RATES.

\section{B. Influence of Recycled Coarse Aggregate on Strength of Recycled Concrete}

From table I and figure IV, V, VI, we can see that life of the recycled coarse aggregate has a certain effect on the strength of recycled concrete. Under the same substitution rate, the compressive strength, splitting tensile strength and flexural strength of 0 years and the 40 years of recycled coarse aggregate concrete cube is higher than that of the 10 years of recycled coarse aggregate concrete. But the strength of 0 years and 40 years of recycled coarse aggregate concrete are close. The reasons for this phenomenon may be as follows: the binding power of Natural coarse aggregate and cement in 0 years of the original concrete is not very strong. Cement is almost completely removed in the process of crushing, and the remaining recycled aggregate is the natural aggregate in the original concrete. With the increase of age, the bond strength of natural aggregate and cement paste increases gradually. In the process of crushing, surface of recycled coarse aggregate will be remaining a part of cement stone of the relatively low strength. And leading to the 10 years recycled coarse aggregate concrete strength decrease. Along with the increase of year and the degree of carbonation of concrete increase, the compressive strength will increase and the recycled coarse aggregate strength is relatively high. 


\section{CONCLUSIONS}

(1) The damage process and failure mode of the recycled concrete cube compressive strength, splitting tensile strength and flexural strength are the same as the ordinary concrete.

(2) In the case of having the same water cement ratio, the recycled concrete cube compressive strength is higher than ordinary concrete and up to $21 \%$. The compressive strength increases with the increase of the substitution rate. But splitting tensile strength is lower than ordinary concrete and the reduction in $25 \%$. With the change of substitution rate, it forms a wave curve; Flexural strength of recycled concrete is close to ordinary concrete, and it is low when the replace rate is $50 \%$.

(3) The life of recycled coarse aggregate has certain effect on the strength of recycled concrete, and the strength of concrete is close to that of 0 years and 40 years. However, 10 years recycled coarse aggregate concrete strength is lower than the former two.

\section{ACKNOWLEDGMENT}

Major research projects of national natural science fund (90715003); The national natural science fund project (10972168); The ministry of education by the specialized research fund for the doctoral program of higher education (200807030002, 20096120120005);Shanxi industrial research project (2008K07-31); Shanxi key laboratory project (08JZ35, 09JS022); State key laboratory open project (08KF02); Key laboratory of visiting scholar project in Shanxi province department of education (09JS023, 09JS024).

\section{REFERENCES}

[1] Yamen Zhang, Honggen Qin. Preliminary Study on the Proportion Design of Recycled aggregate Concrete [J]. Concrete and cement products, 2002 (1): 7-9.

[2] S.Frondistou Yannas. Using waste concrete as aggregate[J].ACI Journal,1977 (74) : 373-376.

[3] Jiabin Li, Jianzhuang Xiao, Zhenping Sun, et al. Research on compressive strength of recycled concrete [J]. Journal of Tongji University, 2004, 32 (12): 1558-1161.

[4] Li Jin. Experimental study on mechanical properties of recycled concrete [J]. New building materials, 2006, (7): 11-13.

[5] Jianzhuang Xiao, Yang Lan. The performance of recycled concrete under uniaxial tension test research [J]. Journal of building materials, 2006, 9 (2): 154-158.

[6] Kawamura $\mathrm{M}$ et al.Reuse of recycled concrete aggregate for pavement[A].Proceedings of the Second International RILEM Symposium on Demolition and Reuse of Concrete and Masonry [C].Tokyo,Japan,1988:585-594.

[7] Ahmad S H.Properties of concrete made with North Carolina recycled coarse and fine aggregates [R].Department of Civil Engineering, North Carolina State University, and June 2004. 